\title{
Análise comparativa de parâmetros físico-químicos e de compostos bioativos em cafés cafeinados e descafeinados
}

\author{
Comparative analysis of physical-chemical parameters and bioactive compounds in caffeinated and \\ decaffeinated coffee
}

Análisis comparativo de parámetros físico-químicos y compuestos bioactivos en el café con cafeína y descafeinado

\author{
Carolina Cabral Angelim \\ ORCID: https://orcid.org/0000-0003-2195-0366 \\ Centro Universitário FIBRA, Brasil \\ E-mail: carolina.995121@gmail.com \\ Paloma Kassia Sousa de Brito \\ ORCID: https://orcid.org/0000-0002-1033-9687 \\ Centro Universitário FIBRA, Brasil \\ E-mail: palomaa.kassia@gmail.com \\ Cláudia Simone Baltazar de Oliveira \\ ORCID: https://orcid.org/0000-0002-1127-5961 \\ Centro Universitário FIBRA, Brasil \\ E-mail: claudiabaltazzar@gmail.com \\ Patrícia Bentes Marques \\ ORCID: https://orcid.org/0000-0003-0951-2822 \\ Centro Universitário FIBRA, Brasil \\ E-mail: marques.ufpa@gmail.com
}

\begin{abstract}
Resumo
O café é uma das bebidas mais comercializadas no mundo, e o consumo elevado desta bebida deve-se aos compostos deste fruto como polifenóis, cafeína e ácido clorogênicos, os quais apresentam propriedades antimutagênicas e antioxidantes. Por essa razão, o objetivo deste trabalho é mensurar e avaliar comparativamente parâmetros físicoquímicos e a presença de compostos bioativos entre cafés cafeinados e descafeinados, a fim de informar se a perda de compostos em cafés torrefatos descafeinados é significativa a ponto de anular suas propriedades ou prejudicar a obtenção das mesmas. Para este fim foram coletadas 12 amostras de cafés cafeinados e descafeinados em 3 supermercados do município de Belém-PA, as quais foram submetidas a testes de $\mathrm{pH}$, índice de refração, umidade, acidez, ácido ascórbico, polifenóis e flavonoides. Os resultados físico-químicos foram expressos em mediana, quartis, mínimo e máximo e os antioxidantes pela média \pm desvio padrão sendo eles: $\mathrm{pH} 5$ e pH 4,87; ${ }^{\circ}$ Brix 1,335 e 1,334; umidade $5,44 \%$ e $5,68 \%$; acidez $10 \mathrm{ml} \mathrm{NaOH} / \mathrm{ml}$ e $11,2 \mathrm{ml} ; 2,10 \%$ e $1,99 \%$ de ácido ascórbico, $213,32 \mathrm{mgEAG} / \mathrm{g}$ e $208,22 \mathrm{mgEAG} / \mathrm{g}$ de polifenóis; $23,8 \mathrm{mg} / 100 \mathrm{~g}$ e $17,6 \mathrm{mg} / 100 \mathrm{~g}$ de antocianinas; $9,79 \mathrm{mg} / 100 \mathrm{~g}$ e $9,73 \mathrm{mg} / 100 \mathrm{~g}$ e de flavonoides amarelos para cafés cafeinados e descafeinados, respectivamente. Conclui-se que cafés descafeinados possuem parâmetros físico-químicos superiores aos cafeinados e inferiores em termos de antioxidantes. Portanto, o consumidor não será prejudicado ao optar por qualquer um deles.
\end{abstract}

Palavras-chave: Análise físico-química; Antioxidantes; Café; Café descafeinado.

\begin{abstract}
Coffee is one of the most commercialized beverages in the world, and the high consumption of this beverage is due to the compounds of this fruit, such as polyphenols, caffeine and chlorogenic acids, which have antimutagenic and antioxidant properties. For this reason, the objective of this work is to measure and comparatively evaluate physicalchemical parameters and the presence of bioactive compounds between caffeinated and decaffeinated coffees, in order to inform whether the loss of compounds in decaffeinated roasted coffees is significant to the point of nullifying its properties or hinder the obtainment of them. For this purpose, 12 samples of caffeinated and decaffeinated coffees were collected in 3 supermarkets in the city of Belém-PA, which were subjected to tests of $\mathrm{pH}$, refractive index, moisture, acidity, ascorbic acid, polyphenols and flavonoids. The physicochemical results were expressed as median, quartiles, minimum and maximum and antioxidants as mean \pm standard deviation, namely: $\mathrm{pH} 5$ and $\mathrm{pH} 4.87$; ${ }^{\circ}$ Brix 1.335 and 1.334 ; humidity $5.44 \%$ and $5.68 \%$; acidity $10 \mathrm{ml} \mathrm{NaOH} / \mathrm{ml}$ and $11.2 \mathrm{ml} ; 2.10 \%$ and $1.99 \%$ ascorbic acid, $213.32 \mathrm{mgEAG} / \mathrm{g}$ and $208.22 \mathrm{mgEAG} / \mathrm{g}$ polyphenols; $23.8 \mathrm{mg} / 100 \mathrm{~g}$ and $17.6 \mathrm{mg} / 100 \mathrm{~g}$ of anthocyanins; $9.79 \mathrm{mg} / 100 \mathrm{~g}$ and $9.73 \mathrm{mg} / 100 \mathrm{~g}$ and yellow flavonoids for caffeinated and decaffeinated coffees, respectively. In conclusion,
\end{abstract}


decaffeinated coffees have physicochemical parameters higher to caffeinated ones and lower in antioxidant levels. Therefore, the consumer will not be harmed choosing anyone of them.

Keywords: Physical-chemical analysis; Antioxidants; Coffee; Decaffeinated coffee.

\section{Resumen}

El café es una de las bebidas más comercializadas en el mundo, y el alto consumo de esta bebida se debe a los compuestos de esta fruta, como polifenoles, cafeína y ácidos clorogénicos, los cuales tienen propiedades antimutagénicas y antioxidantes. Por ello, el objetivo de este trabajo es medir y evaluar comparativamente parámetros físico-químicos y la presencia de compuestos bioactivos entre cafés con cafeína y descafeinados, con el fin de informar si la pérdida de compuestos en los cafés tostados descafeinados es significativa hasta el punto de anulando sus propiedades o entorpeciendo la obtención de las mismas. Para ello, se recolectaron 12 muestras de cafés con cafeína y descafeinado en 3 supermercados de la ciudad de Belém-PA, las cuales fueron sometidas a pruebas de $\mathrm{pH}$, índice de refracción, humedad, acidez, ácido ascórbico, polifenoles y flavonoides. Los resultados fisicoquímicos se expresaron como mediana, cuartiles, mínimo y máximo y los antioxidantes como media \pm desviación estándar, a saber: $\mathrm{pH} 5$ y pH 4,87; ${ }^{\circ}$ Brix 1,335 y 1,334; humedad 5,44\% y 5,68\%; acidez $10 \mathrm{ml} \mathrm{de} \mathrm{NaOH} / \mathrm{ml}$ y $11,2 \mathrm{ml} ; 2,10 \%$ y 1,99\% de ácido ascórbico, 213,32 mg de EAG/g y 208,22 mg de EAG/g de polifenoles; $23,8 \mathrm{mg} / 100 \mathrm{~g}$ y 17,6 mg/100g de antocianinas; $9,79 \mathrm{mg} / 100 \mathrm{~g}$ y $9,73 \mathrm{mg} / 100 \mathrm{~g}$ y flavonoides amarillos para cafés con cafeína y descafeinados, respectivamente. En conclusión, los cafés descafeinados tienen parámetros fisicoquímicos más altos que los cafeinados y más bajos en niveles de antioxidantes. Por tanto, el consumidor no se verá perjudicado por elegir ninguno de ellos.

Palabras clave: Análisis fisicoquímica; Antioxidantes; Café; Café Descafeinado.

\section{Introdução}

O café é uma das bebidas mais comercializadas no mundo, sendo que de todos os países produtores de café, o Brasil ocupa a primeira posição, sendo responsável por cerca de 33,6\% da produção mundial (Penna, 2015). O consumo elevado desta bebida suscita interesse em torno das propriedades destes grãos; algumas das mais conhecidos são os polifenóis, cafeína, ácido clorogênico, lipídeos, minerais e carboidratos (Soares, 2018). Estudos como os de Chaufon et al; 2009 revelam que essas substâncias conferem ao café ação antimutagênica, antioxidante, antibiótica e protetiva contra doenças neurodegenerativas e cardiovasculares.

Dentre os efeitos promovidos por essas substâncias, Araujo e Mancini-Filho (2006) destacam a inibição da biossíntesse dos leucotrienos que atuam em processos inflamatórios, tropismo pela microflora intestinal, estimulação do sistema nervoso central (SNC). A prevenção da carcinogênese é destacada pela presença de antioxidantes como os ácidos clorogênicos e minerais que evitam a degradação e alteração das células, prevenindo o surgimento de mutações que resultem em tumores malignos (Zanin, 2020). Eles atuam como reguladores da proliferação e apoptose de células cancerosas interferir em passos importantes da síntese do DNA e na divisão celular (Segheto, 2017. Gatto et al., 2019).

Outro componente bem descrito é a cafeína, a qual age como antagonista dos receptores de adenosina A1 e A2. Além disso, atua como neuromodulador endógeno, com efeitos inibitórios sobre a excitabilidade central (Silvestre et al., 2018). A cafeína promove liberação de neurotransmissores excitatórios como a dopamina e a adrenalina, ao passo que reduz o limiar de ativação neuronal. Dentre os efeitos benéficos desta substância destacam-se o efeito protetivo contra doenças do SNC como Parkinson e Alzheimer; melhora do rendimento físico devido à ação broncodilatadora e vasoconstrição; melhora da atenção, pelo aumento do estado de vigília e diminuição do cansaço (Trombini \& Oliveira, 2018).

Apesar do valor destas propriedades, descobriu-se, com o tempo, que algumas pessoas possuíam diferentes níveis de tolerância à cafeína. Aqueles que possuem menor tolerância experimentam efeitos adversos como insônia, taquicardia, aumento da ansiedade e problemas gastroesofágicos ao consumi-la. Por essa razão, tornou-se necessário diversificar a produção de café, promovendo produtos com teor reduzido de cafeína e, assim, oferecer uma alternativa menos nociva dessa bebida a esse público. (Kuswardhani et al., 2020).

Em 2010 o consumo de café descafeinado respondia por 10\% do consumo mundial. Atualmente, estima-se que esse valor esteja em torno de $14 \%$. Com valores crescentes desse consumo destaca-se a relevância de aprimorar o conhecimento 
acerca de suas propriedades químicas. O processo de descafeinação utiliza grãos verdes inteiros, antes do processo de torração. Os procedimentos adotados variam desde a extração com água até o uso de solventes como o diclorometano, clorofórmio, etanol e acetona, sendo o diclorometano o mais utilizado no Brasil (Lima, 2010).

Tanto o estudo de Lima (2010) quanto o de Kuswardhani et al. (2020) apontam que durante a extração da cafeína há perda de outros componentes polifenólicos, afetando diretamente o potencial antioxidante dessas bebidas. Nesse sentido, o objetivo deste estudo consiste em mensurar e avaliar comparativamente parâmetros físico-químicos e a presença de compostos bioativos entre cafés cafeinados e descafeinados, destacando os benefícios destes ao organismo. Essa caracterização informará se a perda de compostos em cafés torrefatos descafeinados é significativa a ponto de anular suas propriedades.

\section{Metodologia}

\section{Estudo}

Trata-se de um estudo comparativo, caracterizado como observacional, transversal e analítico. Para delimitar os procedimentos que se seguem neste estudo utilizamos 2 estudos similares, sendo eles: Avaliação de polifenóis e atividade antioxidante do café arábica (Sousa, 2017) e Compostos bioativos e atividade sequestrante de radicais livres de quatro cultivares do coffea arabica em diferentes estádios de maturação dos frutos de (Costa, 2015), além do protocolo Métodos físico-químicos para análise de alimentos do Instituto Adolfo Lutz (2008). As análises foram conduzidas nos laboratórios de Química, Físico-química e Bioquímica da instituição Centro Universitário FIBRA.

\section{Amostras}

A coleta de cafés resultou em 12 amostras, sendo 9 cafeinados e 3 descafeinados, as quais foram obtidas em 3 supermercados do município de Belém que, para esta pesquisa, são denominados supermercados A, B e C. Foram selecionadas 3 marcas de cafés (Marcas 1, 2 e 3) apontadas como as mais consumidas na região de estudo. Para realizar a seleção das amostras utilizamos como critérios de inclusão a data de validade: a durabilidade de no mínimo um ano desde a data em que o produto foi adquirido; o modo de comercialização: embalagem a vácuo; presença do selo de qualidade ABIC. Como critérios de exclusão, adotamos as marcas: selecionamos as marcas de cafés apontadas como as mais consumidas segundo as pesquisas; e o estado de conservação dos pacotes: cafés com a embalagem amassada, rasgada ou furada não foram utilizadas.

\section{Composição físico-química \\ pH e Acidez Titulável}

A análise destes parâmetros seguiu as diretrizes do Instituto Adolfo Lutz - IAL (2008). O pH foi medido diretamente com o auxílio de um pHmetro de bancada da marca Gehaka®, modelo PG1800. A obtenção dos valores de acidez total deu-se mediante titulação com hidróxido de sódio $(\mathrm{NaOH})$ em soluções preparadas com fenolftaleína, igualmente pelas normas do Instituto Adolfo Lutz. O cálculo utilizado para obter os resultados foi feito a partir da fórmula: $\mathrm{V} \times \mathrm{f} \times \mathrm{M} \times 100 / \mathrm{P}=$ acidez em $\mathrm{mL}(\mathrm{V} / \mathrm{V})$, onde: $\mathrm{V}=\mathrm{n}^{\circ}$ de $\mathrm{ml}$ da solução de hidróxido de sódio gasto na titulação, $\mathrm{f}=$ fator de correção da solução de $\mathrm{NaOH}$ $0,1, \mathrm{P}=$ massa da amostra em $\mathrm{g}$ ou volume pipetado em $\mathrm{mL}$ e $\mathrm{M}=$ molaridade da solução de hidróxido de sódio

\section{Índice de refração $\left({ }^{\circ} \mathrm{Brix}\right)$}

Para determinação de sólidos solúveis Brix ('Bx), foi utilizado o método refratométrico pela leitura direta dos graus Brix da amostra a $20^{\circ} \mathrm{C}$ em refratômetro manual RHC-200ATC, de acordo com o método do Instituto Adolfo Lutz (Instituto Adolfo Lutz, 2008). Esta escala permite avaliar a concentração de sólidos como açúcar, sal, proteínas, ácidos dissolvidos em água. O procedimento consiste em ajustar o refratômetro para a leitura de $\mathrm{N}$ em $1,3330 \mathrm{com}$ água a $20^{\circ} \mathrm{C}$, de acordo com as 
instruções do fabricante. A leitura foi realizada por meio de 2 gotas de amostra homogeneizada para o prisma do refratômetro digital, cujo sólidos solúveis é demonstrado na tela do equipamento.

\section{Umidade}

Para determinação da umidade, foi utilizada a metodologia descrita pelo Instituto Adolfo Lutz (2008), por meio da secagem direta em estufa a $105^{\circ} \mathrm{C}$ em duplicata. Em uma balança analítica, foram pesadas $5 \mathrm{~g}$ de cada amostra com duas repetições cada, as quais foram colocadas em cápsula de porcelana previamente tarada. As amostras, em questão, foram aquecidas durante 3 horas e, em seguida, resfriadas em um dessecador com sílica gel até atingir temperatura ambiente. A operação foi repetida até se obter um peso constante. O cálculo utilizado para obter os resultados seguiu a fórmula: \% umidade $=(100 \times \mathrm{N}) / \mathrm{P}$, no qual $\mathrm{N}=\mathrm{n}^{\circ}$ de gramas de umidade (perda de massa em gramas) e $\mathrm{P}=\mathrm{n}^{\circ}$ de gramas de amostra.

\section{Determinação de compostos bioativos}

\section{Determinação do teor de polifenóis}

O teor de compostos fenólicos totais foi determinado através do método colorimétrico Folin-Ciocalteu elaborado por Singleton e Rossi adaptado por Sperotto (2014). Utilizamos $40 \mu \mathrm{L}$ da solução do extrato e adicionamos 3,16 ml de água destilada; $200 \mu \mathrm{L}$ de reagente Folin-Ciocalteu e $600 \mu \mathrm{L}$ de solução de $\mathrm{Na}_{2} \mathrm{CO}_{3}$. A mistura foi agitada por 15 segundos em vórtex e colocada por 30 minutos em banho-maria a $40{ }^{\circ} \mathrm{C}$. Como branco, foi feita essa mistura substituindo o extrato por 40 $\mu \mathrm{L}$ de metanol. Após isso, procedemos a leitura em espectrofotômetro a $765 \mathrm{~nm}$. A equação para curva de ácido gálico foi $\mathrm{y}=$ $0,12 \mathrm{x}-0,14$ em que $\mathrm{R}^{2}=0,973$, e os resultados foram expressos em $\mathrm{mg}$ de ácido gálico/100g de pó de café. (mg de $\mathrm{EAG} / 100 \mathrm{~g})$.

\section{Determinação do teor de compostos flavonoides}

O teor de flavonoides totais foi determinado através da metodologia empregada por Sousa, 2017. Nesse método foi preparada uma solução extratora de HCL a 1,5N. Desta solução foram retirados $150 \mathrm{ml}$ e adicionado em um balão volumétrico de $1000 \mathrm{ml}$, completando com álcool etílico a 95\%. Utilizamos $1 \mathrm{~g}$ da amostra em balão volumétrico de 50ml e completamos o volume com solução extratora. Após agitação foram transferidos $30 \mathrm{~mL}$ da mistura para um tubo de ensaio coberto com papel alumínio, e ficou na geladeira por 16 horas. Após o repouso, realizamos a leitura em espectrofotômetro a 535nm para antocianinas e $374 \mathrm{~nm}$ para flavonoides. Assumimos como branco a solução de etanol/ $\mathrm{HCl}(1,5 \mathrm{~N})$ e os resultados foram expressos em mg/100g, utilizando a equação: Fator de diluição x absorbância/98,2

\section{Determinação ácido ascórbico por iodometria}

Este método está embasado nas diretrizes do Instituto Adolfo Lutz (2008) adaptado pela pesquisadora Dra. Cláudia Baltazar. A análise foi dividida em dois momentos: preparação de extratos das amostras e, posteriormente, avaliação do potencial redutor. Como reagentes, utilizamos uma solução de iodo $5 \%$ e solução de amido igualmente a 5\%. Durante a execução da técnica diluiu-se em béquer de $500 \mathrm{ml} 5 \mathrm{ml}$ do extrato em $10 \mathrm{ml}$ de água destilada, adicionou-se $30 \mathrm{ml}$ da solução de amido e titulou-se com solução de iodo até aparecimento da cor violeta. Utilizamos água com 1000mg de vitamina C como controle e apenas água como branco. $\mathrm{O}$ resultado foi expresso por meio da equação: $\mathrm{V} \times \mathrm{f} \times 8,806 \times 0,1 / \mathrm{P}=\%$ ácido ascórbico $\mathrm{m} / \mathrm{m}$, em que $\mathrm{V}=$ volume de $\mathrm{I}_{2} 0,1 \mathrm{M}$ gasto na titulação, $\mathrm{f}=$ fator da solução de $\mathrm{I}_{2} 0,1 \mathrm{M}$ e $\mathrm{P}=$ massa da amostra em $\mathrm{g}$. A interpretação será qualitativa e seguirá os seguintes parâmetros: < 1 elevada ação antioxidante, 1 a 2 moderada ação antioxidante e >2 baixa ação antioxidante. 


\section{Análise estatística}

Para as análises estatísticas, foi utilizado o programa BioStat 5.0, no qual os dados obtidos foram submetidos ao teste de normalidade d'Agostino. A partir deste resultado, aplicou-se os testes Kruskal-Wallis para as análises físico-químicas e o teste $\mathrm{T}$ para compostos antioxidantes com base nos valores da estatística descritiva. Além destes, foram realizadas análise de correlação através do teste de Pearson e tabulação de dados no programa Excel 2106 da Microsoft Office.

\section{Resultados e Discussão}

Os resultados de análises físico-químicas, obtidos nesta pesquisa foram expressos pela mediana devido a distribuição irregular das amostras de acidez $(\mathrm{p}<0,05)$ conforme a Tabela 1 , a seguir.

Tabela 1. Determinação de parâmetros físico-químicos (pH, brix, acidez e umidade) das amostras cafeinadas e descafeinadas.

\begin{tabular}{|c|c|c|c|c|}
\hline & CAFEINADOS $(\mathrm{n}=9)$ & DESCAFEINADOS $(n=3)$ & $\overline{p \text { (valor) }}$ & $\overline{V R}$ \\
\hline & $\begin{array}{c}\text { MD (Q1 - Q3) } \\
\text { Min - Max }\end{array}$ & $\begin{array}{c}\text { MD (Q1 - Q3) } \\
\text { Min - Max }\end{array}$ & & \\
\hline $\mathrm{pH}$ & $\begin{array}{c}5(4,85-5,1) \\
4,77-5,28\end{array}$ & $\begin{array}{c}4,87(4,77-5,05) \\
4,67-5,24\end{array}$ & 0,52 & pH 5 \\
\hline Refração ( ${ }^{\circ}$ Brix) & $\begin{array}{c}1,335(1,335-1,336) \\
1,334-1,337\end{array}$ & $\begin{array}{c}1,334(1,334-1,334) \\
1,334-1,335\end{array}$ & 0,12 & ausente \\
\hline Acidez \%(v/v) & $\begin{array}{c}10(9,2-11,6) \\
8-13,6\end{array}$ & $\begin{array}{c}11,2(10,8-11,8) \\
10,4-12,4\end{array}$ & 0,45 & ausente \\
\hline Umidade $(\%)$ & $\begin{array}{c}5,44(5,23-5,51) \\
4,76-5,79\end{array}$ & $\begin{array}{c}5,68(5,43-5,80) \\
5,19-5,92\end{array}$ & 0,31 & $5 \%$ \\
\hline
\end{tabular}

Legenda: $\mathrm{MD}=$ Mediana, $(\mathrm{Q} 1-\mathrm{Q} 3)=1^{\circ}$ quartil e $3^{\circ}$ quartil, MIN = valor mínimo, MAX = valor máximo seguidos do valor de $\mathrm{p}$ obtidos no teste Kruskal-wallis com significância de 5\%. Valores de referência obtidos na RDC n 277/2005. Fonte: Autores.

Segundo pesquisas realizadas pela Empresa Brasileira de Pesquisa Agropecuária (EMBRAPA) o solo é um dos principais fatores que condicionam o pH do café. Em uma destas pesquisas, publicadas por Pequeno et al (2011), é destacado que os cultivares de café arábica, conilon e robusta variou de 4,7 a 6 na zona da mata - RO. Segundo Sivetz e Desrosier (1979), as variações de pH com a torração são de suma importância na aceitação do produto pelo consumidor e indicam que o pH ideal é de 4,95 a 5,20 para tornar o café adequado. Dessa forma, nota-se que os valores obtidos nesta pesquisa para cafés cafeinados e descafeinados encontram-se entre os valores propostos pelos autores.

As medianas obtidas em cafés cafeinados (5) e cafés descafeinados $(4,87)$ estão de acordo com a RDC n²77/2005 e são valores próximos aos de Rodrigues (2012) que teve valores de 5,28-5,84 em cafés descafeinados na análise de composição química do café realizada no alto vale do Jequitinhonha. Além deste, a análise de Souza e Moreira (2018), mostrou valores inferiores ao de Rodrigues, porém semelhantes aos resultados desta pesquisa, sendo de 4,94 a 5,08 para amostras cafeinadas e 4,87 a 4,08 para descafeinadas. Índices inferiores ao de Seixas e Junior (2021), que foi de 5,29 para amostras descafeinadas obtidas no estado da Bahia.

A acidez é um parâmetro de qualidade em alimentos, pois indica o estado de conservação e se houve processos de degradação (IAL, 2008). Além disso, trata-se de um índice influenciado pelo grau de torrefação do café e sua espécie (Seixas e Junior, 2021). Os valores de acidez titulável encontrados nesse trabalho foram de $8 \%$ a 13,6\% em cafés cafeinados e 10,4\% a 12,4\% em cafés descafeinados. Esses valores se assemelham aos resultados encontrados por Silva et al (2019) na avaliação microscópica e físico-química de cafés torrados e moídos de Sete Lagoas-MG que obteve resultados de 8,21 a 14,63 em amostras embaladas a granel e 11,92 a 32,62 nas embaladas industrialmente. Os valores obtidos nesta análise são superiores 
aos de Seixas e Júnior (2021), o qual obteve variação de 1,11\% v/v a 4,2\% v/v em infusões de café descafeinado, e inferiores aos de Rodrigues (2012) que teve média de 269,90ml de NaOH 0,1N/100g em amostras de café de Diamantina-MG.

Os valores de brix $\left({ }^{\circ}\right)$ de café ainda não apresentam um valor devidamente definido que represente a qualidade do produto, pois várias características podem influenciar no resultado, como: fatores físicos, químicos e sensoriais do café. Contudo, observou-se que os valores obtidos nesta análise foram inferiores aos valores de Dantas (2017) que obteve entre 1,4755 até $1,4810^{\circ}$ Brix. Atribuímos essa diferença ao tipo de café analisado em seu estudo: cru e verde, portanto, sujeitos a menor processamento. Em pesquisa similar ao de Dantas, realizada por Sanchez (2016), o índice de refração variou de 1,4790 a 1,4792 em amostras de café arábica do estado de Minas Gerais. Ambas analisaram óleos extraídos de café arábica, o que pressupõe uma correlação com outros parâmetros, tais como: densidade e sólidos solúveis totais.

A umidade, assim como as demais análises físico-químicas supracitadas, é de grande importância na indústria cafeeira. A quantidade de água presente neste alimento influencia diretamente na proliferação de microrganismos (Pinto, Veiga e Souza, 2019). Os resultados obtidos neste trabalho revelam que poucas amostras possuíam valor de umidade dentro da referência estabelecida pela RDC $n^{\circ}$ 277/2005. Atribuiu-se isto a dois fatores: vedação insuficiente das amostras e o clima da região de estudo, caracterizado pela elevada umidade, inferindo ganho de umidade do meio nas amostras. Apesar disso, todas as amostras possuem o selo ABIC, o que garante que passaram por vistoria criteriosa antes de chegar ao consumidor.

Estes resultados são similares com os obtidos nas análises promovidas por Silva et al (2019). Nesta, os valores de umidade variaram 4,93 a 5,53 em amostras embaladas industrialmente e 3,95 a 6,47 nas embaladas a granel. Contudo, diferem dos resultados obtidos por Agnoletti et al (2019) que oscilaram entre 1,33 e 2,82 em cafés torrados e valor máximo de 12,01 em amostras cruas. Já os valores obtidos na pesquisa de Seixas e Júnior (2021) tiveram mínima de 3,07 e máxima de 4,60 em amostras descafeinadas da feira de Santana-BA, que foram resultados próximos aos dessa pesquisa.

Após esses procedimentos foram realizadas as análises para determinar as concentrações de compostos com ação e/ou potencial antioxidante. Para estas análises utilizou-se a média como referência devido a distribuição regular das amostras determinada pelo teste d'Agostino conforme demonstrado na Tabela 2.

Tabela 2. Determinação de compostos com atividade antioxidante.

\begin{tabular}{lccc}
\hline & CAFEINADOS (n=9) & DESCAFEINADOS (n=3) & p (valor) \\
\hline & $\bar{M} \pm$ DP & $\bar{M} \pm$ DP \\
& Min - Max & $1,99 \pm 0,13$ & \\
\cline { 2 - 4 } Ácido ascórbico $\%(\mathrm{~m} / \mathrm{m})$ & $2,10 \pm 0,15$ & $1,58-2,30$ & 0,48 \\
& $1,87-2,27$ & $208,22 \pm 3,5$ & 0,26 \\
Polifenóis (mg de EAG/g) & $213,32 \pm 6,9$ & $204,94-211,9$ & 0,28 \\
& $205,42-223,06$ & $17,63 \pm 10,34$ & $0,2-126,2$ \\
Antocianinas (mg/100g) & $23,8 \pm 10,28$ & $9,73 \pm 0,05$ & 0,30 \\
Flavonoides amarelos (mg/100g) & $4,39-36,1$ & $9,65-9,78$ & 0 \\
\hline
\end{tabular}

Média das amostras \pm desvio padrão; seguidas do valor de p, obtido no Teste T Student, com significância de 5\%. Fonte: Autores.

O fundamento da técnica iodimetria, utilizada para dosar o ácido ascórbico, é a volumetria redox. Essa titulação é utilizada para verificar o teor de antioxidantes presentes nas amostras. Neste tipo de dosagem o iodo age como titulante e a solução de amido como indicador da reação, ao se complexarem forma-se um composto colorido de coloração azul/roxa (Silva, 2019). Durante a titulação com iodo a média das amostras cafeinadas foi de $2,10 \mathrm{mg} / \mathrm{g}$ sendo 1,87 o menor valor obtido e 2,27 o maior. Entre as amostras descafeinadas a média foi de 1,99mg/g, com valores mínimo e máximo de 1,58 e 2,30 respectivamente. Estes resultados encontram-se inferiores aos de Malvessi (2019), a qual obteve resultados que variaram de 7 a 
250mg/mL de ácido ascórbico (AA) em amostras de Blumenau-SC. Porém encontram-se próximas aos de Sousa (2017) que em seu estudo encontrou mínima de 3,99 e máxima de 5,92mg/100g de AA em amostras de Redenção-CE.

A capacidade antioxidante ligada aos polifenóis deve-se a sua capacidade de estabilizar radicais livres a partir da doação de íons $\mathrm{H}^{+}$ou elétrons (Sperotto, 2014). Durante esta pesquisa notou-se que estes são os compostos de maior prevalência nas amostras comerciais de café, sendo elas cafeinadas ou não. Os resultados variaram de 205,42 a 223,06mg de EAG/g entre cafés cafeinados e de 204,94 a 211,90mg de EAG/g em cafés descafeinados. Esses valores são condizentes aos obtidos por Sousa (2017), que também foram representativos em sua pesquisa com valores entre 448,17 e 544,73 mg de EAG/g. Contudo, são valores superiores aos obtidos por Agnoletti et al (2019) em que os resultados variaram de 2,97 a 6,80g de EAG/100g (aproximadamente 29,7 e $68 \mathrm{mg} / \mathrm{g}$ ).

Outro estudo que exibiu resultados similares aos desta pesquisa foi o de Romero (2017) em caracterização química e funcional de amostras cafeinadas de café Nestlé em Lisboa-PT. Suas análises demonstram que o índice de compostos fenólicos varia de 19,5 a 382,1mg EAG /g de extratos acéticos em concentrações de 10-100\%. Ademais, os resultados de Braga, Fael e Pinto (2017), embora utilizando ácido tânico como referência em vez de ácido gálico, apresentam valores próximos aos desse estudo variando de 152,4 a $357 \mathrm{mg}$ de ATE/g entre cafés descafeinados e 271,9 a 599,5 mg de ATE/g entre cafés cafeinados do tipo tradicional.

Os flavonoides foram analisados a partir da reação com a solução extratora de $\mathrm{HCl}$ com álcool etílico, a qual solubiliza diversos compostos do café permitindo sua análise (Borsatti,2015). Neste trabalho os flavonoides foram subdivididos entre antocianinas e flavonoides amarelos, e as análises retornaram com os seguintes resultados: média das antocianinas em amostras cafeinadas de 23,8 mg/100g e de 17,63mg/100g em descafeinadas. Já os flavonoides amarelos não apresentaram grande diferença entre si, variando de $9,79 \mathrm{mg} / 100 \mathrm{~g}$ em amostras cafeinadas a $9,73 \mathrm{mg} / 100 \mathrm{~g}$ em descafeinadas.

Os resultados das antocianinas são inferiores aos obtidos por Sousa, F. A (2017), que obteve mínima de 172,60 e máxima de $180,27 \mathrm{mg} / 100 \mathrm{~g}$ em amostras cafeinadas. Contudo, obteve valores próximos para flavonoides amarelos, que variaram de 12,67 a 24,89mg/100g nessas mesmas amostras. Já os resultados obtidos por Sousa, F. J. (2017) demonstram uma inversão de concentrações, na qual os valores de antocianinas $(28,31 \mathrm{mg} / 100 \mathrm{~g})$ foi menor que o de flavonoides amarelos $(74,68 \mathrm{mg} / 100 \mathrm{~g})$. Ambas os trabalhos utilizaram a mesma metodologia e foram realizados com amostras de café de RedençãoCE.

Observa-se que, ainda que sutis, há diferenças entre os valores obtidos entre cafés cafeinados e descafeinados, com destaque para os compostos antioxidantes. Isso se deve a uma relação intrínseca com a cafeína, que segundo de Maria \& Moreira (2004) está complexada ao clorogenato que é a forma purificada do ácido clorogênico - um ácido fenólico. Por essa razão, subentende-se que o processo de descafeinação mais comum no Brasil, realizada com diclorometano (DCM), subtrai diversos compostos fenólicos, além de proteínas e açúcares, tornando este produto menos atrativo em termos de nutritivos. Além da descafeinação com DCM, há também com água e carvão ativado, dióxido de carbono supercrítico e ultrassom com o objetivo de reduzir essas perdas e preservar propriedades organolépticas da bebida (Henao, 2015) Além desta constatação, foi possível determinar correlações entre os parâmetros analisados, como demonstrado na Figura 1. 
Figura 1. Determinação de correlação entre pH e Acidez (a) e índice de refração e umidade (b).

Correlaçăo Linear de Pearson

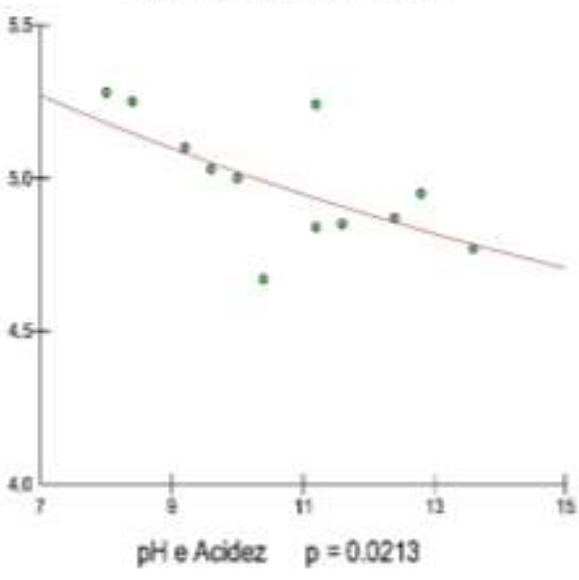

Correlaçåo Linear de Pearson

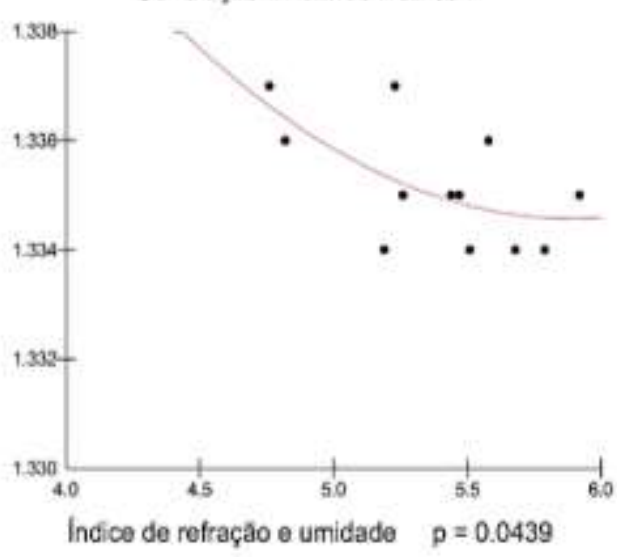

(b)

Índice de correlação em entre pH e acidez determinado pelo fator r (Pearson) de -0,6529 e no índice de refração e umidade por -0,5888. Fonte: Autores.

Com base nos resultados obtidos no teste de correlação linear de Pearson com significância de 5\% constatou-se que a correlação entre os dados de $\mathrm{pH}$ e acidez são inversamente proporcionais, indicando que, quanto menor o pH maior a acidez. Analisando a correlação do índice de refração e umidade observou-se uma exponencial decrescente, em que, quanto maior o teor de água presente nas amostras, mais próximo do valor de refração da água em graus Brix $\left(1,333^{\circ}\right)$ elas estavam.

\section{Conclusão}

Os resultados deste trabalho permitiram concluir que a descafeinação promove mudanças em cafés de grande comercialização. Inferiu-se que possuem valores acima dos cafeinados nas análises de pH, acidez titulável, índice de refração, umidade e que apresentam uma quantidade inferior de substâncias antioxidantes como polifenóis, flavonoides e ácido ascórbico quando comparados aos cafés cafeinados. Nesse sentido, esta pesquisa é relevante para elucidar aspectos funcionais deste fruto de grande importância comercial, possibilitando uma escolha mais consciente destes produtos.

Destacamos ainda a abrangência do tema, possibilitando a avaliação de diversos outros aspectos do café e subprodutos sob diferentes variáveis. Portanto, é desejável que futuros trabalhos sobre este fruto busquem maior compreensão do assunto através de análises mais sensíveis, análises macroscópicas, microscópicas a fim de que sejam analisados demais compostos e atividade antioxidante do café. Ademais, destacamos a importância de ensaios clínicos para aprimorar o conhecimento sobre a interação dos compostos do café com o organismo.

\section{Referências}

Abrahão, S. A., Pereira, R. G. F. A., Lima, A. R., Ferreira, E. B., \& Malta, M. R. (2008). Compostos bioativos em café integral e descafeinado e qualidade sensorial da bebida. Pesquisa agropecuária brasileira, 43, 1799-1804.

Anunciação, A. S., \& da Silva Júnior, L. S. (2016, dezembro). Análise da qualidade do café obtido por torrefação a vácuo. In Revista do Congresso Sul Brasileiro de Engenharia de Alimentos (Vol. 2, No. 1).

Agnoletti, B. Z., Oliveira, E. D. S., Pinheiro, P. F., \& Saraiva, S. H. (2019). Discriminação de café arábica e conilon utilizando propriedades físico-químicas aliadas à quimiometria. Revista Virtual de Química, 11(3), 785-805.

Araújo, F. A., \& Mancini Filho, J. (2006). Compostos bioativos do café e seus benefícios à saúde. Hig. alim., 60-65.

Borsatti, F. C., Mazaro, S. M., Danner, M. A., Nava, G. A., \& Dalacosta, N. L. (2015). Indução de resistência e qualidade pós-colheita de amora-preta tratada com ácido salicílico. Revista Brasileira de Fruticultura, 37, 318-326. 
Brasil. Agência Nacional de Vigilância Sanitária. RDC no 277, de 22 de setembro de 2005. Aprova o "Regulamento técnico para café, cevada, chá, erva-mate e produtos solúveis". Diário Oficial da União, Brasília, n. 184, 23 set. 2005.

Braga, A. V. A., de Almeida Fael, S. F., \& Pinto, L. C. (2017). Variação de teor de compostos fenólicos totais em diferentes tipos de café processados. Nutrição Brasil, 16(2), 94-99.

Chalfoun, S. M., Pimenta, C. J., Oliveira, R. M., Pimenta, M. E. D. S., Mendonça, M. C., Parreira, C. R., \& Pereira, M. C. (2009). Influência da cafeina nos níveis séricos de ácido urico e glicose em indivíduos adultos, ativos e sedentários. VI Simpósio de Pesquisa dos Cafés do Brasil. Vitória, ES, Brasil, 6.

Dantas, R. C. (2017). Caracterização físico-química do óleo de café verde. Monografia de graduação, Universidade Federal do Rio Grande do Norte, Natal, RN, Brasil. https://repositorio.ufrn.br/bitstream/123456789/38250/2/Caracteriza\%C3\%A7aoOleo_Dantas_2017.pdf.

Gatto, M. A., Medeiros, J. V., \& de Souza, F. P. Analisando os benefícios do consumo de café para a saúde humana. https://www.inesul.edu.br/revista/arquivos/arq-idvol_64_15687 31056.pdf.

Henao, C. P. (2015). Efeito do processo de descafeinação de café arábica em meio aquoso auxiliado por ultrassom sobre a composição quimica e o perfil sensorial. Universidade Estadual Paulista Júlio de Mesquita Filho, São José do Rio Preto, SP, Brasil. https://docs.google.com/ viewerng/viewer?url=http://www.sbicafe.ufv.br/bitstream/handle/123456789/11978/Dissertacao_Carolina+Perez+Henao.pdf?sequence\%3D1\&isAllowed=y

Instituto Adolfo Lutz (IAL) (2008). Métodos físico-químicos para análise de alimentos. ANVISA. https://wp.ufpel.edu.br/nutricaobromatologia/files/2013/07/NormasADOLFOLUTZ.pdf

Kuswardhani, N., Mukti, N. P., \& Sari, P. (2021). Antioxidant and sensory properties of ready to drink coffee-ginger made from decaffeinated and nondecaffeinated robusta coffee beans. IOP Conference Series: Earth and Environmental Science. 653(1), 012050.

Lima, A. R., Pereira, R. G. F. A., Abrahão, S. A., Duarte, S. M. D. S., \& Paula, F. B. D. A. (2010). Compostos bioativos do café: atividade antioxidante in vitro do café verde e torrado antes e após a descafeinação. Química Nova, 33(1), 20-24.

Malvessi, G. S. (2019). Desenvolvimento de dispositivos em papel para análise qualitativa e semiquantitativa de antioxidante. Trabalho de Conclusão de Curso, Universidade Federal de Santa Catarina, Blumenau, SC, Brasil. https://repositorio.ufsc.br/handle/123456789/199717

Penna, A. M. M. (2015). Avaliação do potencial de grãos defeituosos de café como substratos na produção de fibras com potencial antioxidante. Dissertação de mestrado, Universidade Federal de Minas Gerais, Belo Horizonte, MG, Brasil. Disponível: https://repositorio.ufmg.br/bitstream/1843/BUBD-A5GLD2/1/ disserta_o_definitiva.pdf.

Pequeno, P. L. de L., Reis, D. N., Schlindwein, J. A., Locatelli, M., Leonidas, F. das C., Vieira, A. H. Avaliação do PH, K, Ca + Mg de áreas com cafeeiro na Zona da Mata de Rondônia. XXXIII Congresso Brasileiro de Ciência do Solo. Uberlândia, MG, Brasil, 33.

Pinto, F. L., Veiga, W. A., \& de Souza, V. R. S. (2019). Análise das características físico-químicas e microscópicas de café arábica produzidos na região noroeste fluminense e região da zona das matas de minas gerais. Revista Interdisciplinar Pensamento Científico, 5(4).

Rodrigues, I. R. (2012). Composição química do café do Alto Vale do Jequitinhonha e comparação dos efeitos sub-crônicos da cafeína e do café em ratos. Dissertação de mestrado, Universidade Federal dos Vales do Jequitinhonha e Mucuri, Diamantina, MG, Brasil. http://sbicafe.ufv.br/ bitstream/handle/123456789/11498/Dissertacao_Iara\%20Ribeiro\%20Rodrigues.pdf?sequence=1\&isAllowed=y.

Romero, N. G. (2017). Extração de compostos fenólicos a partir de café e sua caracterização química e funcional. Tese de doutorado, Universidade Nova de Lisboa, Lisboa, Portugal. Disponível: https://run.unl.pt/bitstream/10362/22178/1/Romero_2017.pdf.

Sanches, M. Z. (2016). Avaliação das características físico-químicas e sensoriais de óleo de café torrado (Coffea arabica) durante armazenamento em diferentes temperaturas. Dissertação de mestrado, Universidade Tecnológica Federal do Paraná, Londrina, PR, Brasil. http://riut.utfpr.edu.br/jspui/ bitstream/1/2236/1/LD_PPGTAL_M_Sanches\%2C\%20Marcelo\%20Zuchi_2016.pdf.

Seixas, L. S., \& da Silva Junior, L. S. (2021). Aplicação de métodos de análise físico-química para avaliação de cafés descafeinados. Brazilian Journal of Development, 7(6), 63869-63882.

Silva, J. C., Silva, N. A. B., dos Reis Silva, S. L., Silva, L. S., Junqueira, M. S., \& Trombete, F. M. (2019). Avaliação microscópica e físico-química de café torrado e moído comercializado em Sete Lagoas-MG. Scientia Plena, 15(6).

Silva, R. S., Pedroso, A. V., de Jesus, P. C., Gelinski, J. M. L. N., \& Borges, E. M. (2019). Determinação de Vitamina C em Suplementos Alimentares Utilizando Métodos Volumétricos e Espectrofotometria de Absorção Molecular. Revista Virtual de Química, 11, 155.

Silvestre, J. C., Gianoni, R., \& Pereira, P. E. (2018). Cafeína e desempenho físico: metabolismo e mecanismos de ação. Revista Brasileira de Fisiologia do Exercício, 17(2), 130-137.

Siqueira, H. H. D., \& Abreu, C. M. P. D. (2006). Composição físico-química e qualidade do café submetido a dois tipos de torração e com diferentes formas de processamento. Ciência e Agrotecnologia, 30, 112-117.

Soares, M. J. (2018). Avaliação do efeito da adição de ingredientes sobre os compostos fenólicos e a capacidade antioxidante de cápsulas de café expresso e sua bioacessibilidade. Dissertação de mestrado, Universidade de São Paulo, São Paulo, SP, Brasil. Disponível: https://teses.usp.br/teses/disponiveis /6/6138/tde-16102018-142246/pt-br.php.

Sivetz, M., \& Desrosier, N. W. (1979, novembro). Coffee technology. Avi.

Sousa, F. A. D. (2017). Avaliação de polifenóis e atividade antioxidante do Café Arábica (Coffea arábica). Monografia, Instituto de desenvolvimento Rural da Universidade da Integração Internacional da Lusofonia Afro-Brasileira do Ceará, Redenção, CE, Brasil. https://repositorio.unilab.edu.br/ jspui/bitstream/ 123456789/919/1/Francisco\%20Acacio\%20TCC_Agronomia.pdf. 
Research, Society and Development, v. 10, n. 16, e256101623939, 2021

(CC BY 4.0) | ISSN 2525-3409 | DOI: http://dx.doi.org/10.33448/rsd-v10i16.23939

Souza, R. C.; Moreira, V. D. (2018). influência do sombreamento do café agroecológico nas características sensoriais e fisico-químicas da bebida. ciência e tecnologia de alimentos. Trabalho de Conclusão de Curso, Instituto Federal de Educação Ciência e Tecnologia do Sudeste de Minas Gerais, Rio Pomba, MG, Brasil. https://www.ifsudestemg.edu.br/documentos-institucionais/unidades/riopomba/departamentos-academicos/ciencia-e-tecnologia-de-alimentos/ciencia-etecnologia-de-alimentos/2018/influncia_do_sombreamento_do_caf_agroecolgico_nas_caractersticas_fsico-qumicas_e_sensoriais_da_bebi da.pdf

Sperotto, R. A. (2014). Protocolos e métodos de análise em laboratórios de biotecnologia agroalimentar e de saúde humana. Editora da Univates. Lajeado-RS.

Trombini, C. B., \& de Oliveira, G. G. (2018). Atualização terapêutica sobre a cafeína. Revista Terra \& Cultura: Cadernos de Ensino e Pesquisa, 29(57), 1122.

Zanin, T (2021). Beber 3 xícaras de café por dia reduz risco de câncer. https://www.tuasaude.com/cafe-diminui-risco-de-cancer. 